\title{
Swallowing and Aspiration: How Much Is Affected by the Number of Arytenoid Cartilages Remaining After Supracricoid Partial Laryngectomy?
}

\author{
Caner Kılıç $\cdot$ Ümit Tunçel ${ }^{1} \cdot$ Metin Kaya $^{2} \cdot$ Ela Cömert $^{1} \cdot$ Samet Özlügedik $^{1}$ \\ ${ }^{1}$ Department of Otorhinolaryngology, Ankara Dr. Abdurrahman Yurtaslan Oncology Training and Research Hospital, Ankara; \\ ${ }^{2}$ Batman Government Hospital, Batman, Turkey
}

Objectives. The aim of this study was to compare the effect of the presence of one or two arytenoids on early/late period swallowing-aspiration functions.

Methods. Supracricoid partial laryngectomy (SCPL) with the diagnosis of laryngeal cancer between 2012 and 2014 were retrospectively evaluated. The patients were categorized into two groups as follows: group I, patients who underwent SCPL with one arytenoid cartilage and group II, patients who underwent SCPL with two arytenoid cartilages. The time of decannulation and oral feeding onset, and swallowing-aspiration functions were evaluated and compared in the early nutritional period, first, and third months.

Results. There was no significant correlation between decannulation time and swallowing-aspiration. The aspiration rates in group I and group II were similar and there was no significant difference in oral feeding onset and aspiration grades in the first and third months between both groups.

Conclusion. We found similar oncological and functional outcomes in SCPL which protected one or two arytenoid cartilages. Therefore we suggest to be performed one arytenoid cartilage SCPL in selected patients who was advance stage and tumor volume over with larynx cancer.

Keywords. Arytenoid; Aspiration; Partial Laryngectomy; Swallowing

\section{INTRODUCTION}

It is fundamental to provide patients with optimum quality of life following laryngeal cancer therapy. Therefore, it is highly important to perform organ-preserving operations, as well as to resolve the disease. Supracricoid partial laryngectomy (SCPL) is a good alternative for the treatment of T2 and limited T3 stage laryngeal cancer patients who are difficult to control using radiotherapy (RT).

\footnotetext{
- Received November 30, 2015

Revised June 7, 2016

Accepted June 10, 2016

- Corresponding author: Caner Kılıç

Department of Otorhinolaryngology, Ankara Dr. Abdurrahman Yurtaslan Oncology Training and Research Hospital, Mehmet Akif Ersoy district 13,

St. No. 56, 06200 Yenimahalle/Ankara,Turkey

Tel: +90-312-336-0909, Fax: +90-312-334-0352

E-mail: canerkilic80@gmail.com
}

The aim of this surgery is to reintegrate patients into social life by safely removing the tumor, leaving a functional organ, and providing physiological functions of speech, swallowing, and aspiration. Therefore, arytenoid cartilage and at least one functional arytenoid should not be infiltrated with the tumor in order to perform this surgery. Preservation of the hyoid bone varies depending on tumor prevalence [1].

Swallowing problems of SCPL patients are the main cause for hospitalization; oral feeding, which begins on day 7 , can be prolonged to 35-40 days. This leads to increased treatment costs [2]. To avoid this prolonged healing period, and achieve functional swallowing after surgery, the twelfth cranial nerve and nervus laryngeus superior-inferior should remain intact, and cartilage structures should be covered with mucosa to the greatest extent possible [3].

The decannulation of the patients who were operated on using this technique is important in order to begin nutrition. The

Copyright (C) 2017 by Korean Society of Otorhinolaryngology-Head and Neck Surgery.

This is an open-access article distributed under the terms of the Creative Commons Attribution Non-Commercial License (http://creativecommons.org/licenses/by-nc/4.0)

which permits unrestricted non-commercial use, distribution, and reproduction in any medium, provided the original work is properly cited. 
decannulation occurs on different days depending on arytenoid edema; early decannulation allows for the protection of the cough reflex, and early arytenoid mobilization (by increasing larynx). This, in turn, leads to the development of swallowing, and decreases aspiration.

In the literature, there are different results on the effect of the presence of arytenoids on function. It was reported that decannulation time and aspiration grades were longer in SCPL patients with one arytenoid compared to SCPL patients with two arytenoids [4]. In the light of this theoretical information, patients with two arytenoids were considered to have a better swallowing function. However, we believe that SCPL patients with one arytenoid have better swallowing-aspiration functions; therefore in this study, we aimed to present the swallowing-aspiration functions in early and late period and the surgical outcome in SCPL patients with one arytenoid and two arytenoids.

\section{MATERIALS AND METHODS}

The medical records of 37 patients who underwent SCPL with the diagnosis of laryngeal cancer between 2012 and 2014 were retrospectively evaluated. There were $35(94 \%)$ male patients, and 2 female patients $(6 \%)$. All patients lesion, was localized in supraglottis. According to the American Joint Committee on Cancer (AJCC) 2010, 26 patients (70\%) were stage T3 and 11 patients (30\%) were stage T2.

Twenty-five patients (67\%) underwent SCPL with two arytenoids and 12 patients (32\%) underwent SCPL with one arytenoid. These patients were categorized into two groups as follows: group I and group II. Group I included patients who underwent SCPL with one arytenoid cartilage; group II included patients who underwent SCPL with two arytenoid cartilages. Patients were decannulated on days 7-12 regarding any postoperative complications (air leak into neck, re-exploration). Oral feeding with soft and solid food was started on days 9-15 depending on decannulation time. The nasogastric tube was removed from the patients who were considered to have adequate oral feeding. Swallowing-aspiration functions of all patients were assessed according to the Pearson [5] and Leipzig [6] aspiration scale (grade

\section{H I G H L I G G H T T S}

- The decannulation time and time to start enteral nutrition were similar in both groups.

- Aspiration rates were better in the group I with one arytenoid removal.

- In this study we found similar oncological and functional outcomes in supracricoid partial laryngectomy (SCPL).

- We suggest to be performed one arytenoid cartilage SCPL in selected patients.

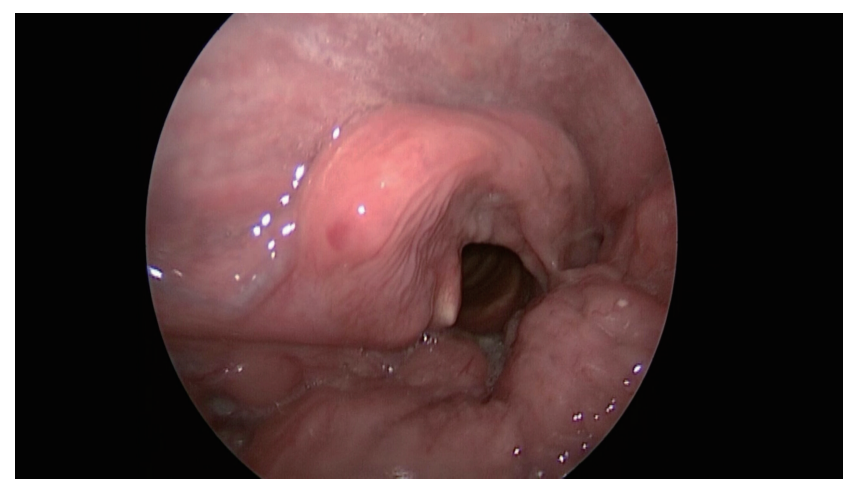

Fig. 1. One-quarter of the posterior vocal cord was left in front of the intact arytenoid.

1 , no aspiration; grade 2, rare cough, no serious problem; grade 3 , apparent cough increased with nourishment; grade 4, pneumonia). Aspiration was scored in the early period (onset of first enteral nutrition), first month, and third month.

The study did not include patients receiving postoperative radiotherapy or chemoradiotherapy. However, 2 patients had received preoperative radiotherapy. All patients underwent bilateral lateral neck dissection (level 2, 3, 4), $\mathrm{N}$ stage of these patients were N0 and N1.

One-quarter of the posterior vocal cord was left in front of the intact arytenoid (Fig. 1). To prevent their deviation to the posterior cricoid, arytenoids were sutured by using a vicryl suture. Cricohyoidopexy was performed on 36 patients (97\%) for reconstruction. On the other hand, cricoglossopexy was performed on 1 patient (3\%) for reconstruction (as the hyoid bone was added into the specimen). The pyriform sinus mucosa was sutured without a gap by using 4.0 vicryl. A nasogastric tube was used for nutrition in the early postoperative period.

\section{Statistical analysis}

The SPSS ver. 15.0 (SPSS Inc., Chicago, IL, USA) was used for statistical analysis. The Kolmogorov-Smirnov test was used to test whether the groups fit a normal distribution. The oneway ANOVA test was used to analyze the effect of univariates on swallowing. The Wilcoxon test was used to analyze the effects of time on swallowing. The Mann-Whitney $U$-test was used to determine the differences between the groups. The $P$-value $<0.05$ was considered significant.

\section{RESULTS}

The age of the patients ranged between 44-69 years, and the median age was $55 \pm 7$ years. In both groups, age did not have a significant effect on aspiration in early feeding period, first month, and third month $(P=0.463, P=0.333$, and $P=0.999$, respectively). Patients in group I were decannulated on days 7-12 
Table 1. Group I and group II patients swallowing phases

\begin{tabular}{lccc}
\hline Variable & Group I (\%) & Group II (\%) & $P$-value \\
\hline Early enteral nutrition & & & 0.643 \\
Grade 1 & - & - & \\
Grade 2 & $3(25)$ & $8(32)$ & \\
Grade 3 & $7(58)$ & $13(52)$ & \\
Grade 4 & $2(16)$ & $4(16)$ & \\
First month & & & 0.786 \\
Grade 1 & - & - & \\
Grade 2 & $5(41)$ & $12(48)$ & \\
Grade 3 & $6(50)$ & $11(44)$ & \\
Grade 4 & $1(8)$ & $2(8)$ & \\
Third month & & & 0.451 \\
Grade 1 & $11(91)$ & $21(84)$ & \\
Grade 2 & $1(9)$ & $4(16)$ & \\
Grade 3 & - & - & \\
Grade 4 & - & - & \\
\hline
\end{tabular}

(7.6 \pm 1.6$)$, and patients in group II were decannulated on days 7-12 (8.2 \pm 1.8$)$. There was no difference in time to decannulation between the groups correlation between decannulation time and swallowing-aspiration $(P=0.040)$

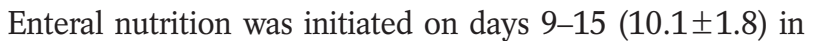
group I, and on days 9-15 (10.4 \pm 2.0$)$ in group II. There was no difference in time to start feeding between the groups $(P=0.563)$.

We compared the aspiration grades in group I at the onset of first enteral nutrition, first month, and third month. At the third month, $91 \%$ of the patients had complete feeding (Table 1). Similarly, we compared the aspiration grades in group II at the onset of first oral feeding, first month, and third month. At the third month, $84 \%$ of the patients had complete feeding (Table 1).

In both groups, the swallowing-aspiration rates were significantly better in the first month compared to first enteral nutrition $(P=0.005)$. In both groups, swallowing-aspiration in the third month was significantly better compared to first month $(P<0.005)$.

There was no significant difference in first enteral nutrition grade between group I and group II $(P=0.643)$. Similarly, we did not find significant differences in first month feeding rates $(P=0.786)$ and third month feeding rates $(P=0.451)$ between group I and group II. In group II, 2 patients $(5 \%)$ received preoperative RT. These patients had aspiration scores of grade 4 in early nutrition period, grade 2 in the first month, and grade 2 in the third month.

\section{DISCUSSION}

Enteral nutrition was provided at an optimal level in all patients, including those who underwent endolaryngeal laser surgery (due to larynx surgery) or total laryngectomy [7]. On the other hand, in late stage tumors, speech and the physiological airway cannot be protected due to organ loss, and this has a negative effect on the social adaptation of patients. Thus, organ-protective surgeries are important, and surgeons should push the limits in oncological conditions as far as possible. SCPL is contraindicated in cases of tumor spreading to the upper boundary of the cricoid cartilage/invasion of cricoid cartilage, posterior commissure involvement, tumor spread to the outer perichondrium of the thyroid cartilage, hyoid bone, or outside larynx. If these anatomical structures are not involved, SCPL preserving a single arytenoid (in oncological boundaries) should be considered before total laryngectomy, to maintain physiological airway and speech.

Different authors, including Marchese-Ragona et al. [8], O'Neil et al. [9], and Rosenbek et al. [10] have reported different scales for scoring aspiration-swallowing. The Pearson [5] and Leipzig [6] scoring, which was also used in the current study, is frequently used in the literature.

According to the literature [11], the mean decannulation time for patients who undergo SCPL ranges between 9-30 days. Aygenc et al. [3] reported that the resection of arytenoid cartilage has no significant effect on decannulation time. In the present study, the mean decannulation time was 7.2 days in group I, and 8.2 days in group II. These findings were consistent with the literature, and the decannulation time in both groups had no significant effect on aspiration.

Different studies have reported contradictory effects of age on aspiration in patients who undergo SCPL. Naudo et al. [12] have reported that age greater than 70 years has a negative effect on decannulation time and aspiration similarly, Alajmo et al. [13] have reported that age has a significant effect on aspiration. On the other hand, Schindler et al. [14] stated that age has no significant effect on aspiration. In the present study, we did not find a significant effect of age on swallowing-aspiration in early period (onset of first enteral nutrition), first month, and third month.

Pellini et al. [15] reported that the rate of aspiration and other complications are higher in patients who received preoperative RT. On the other hand [16], another study has reported that RT increases the risk, but has no significant effect. In the present study, 2 patients $(5 \%)$ who had mild aspiration problems in third month were receiving RT. These findings indicate that RT is associated with a higher risk for aspiration, but were not sufficient to draw a statistically significant conclusion.

Previous studies have reported different incidences of aspiration in patients who underwent SCPL. According to Pellini et al. [15], the incidence of temporary aspiration ranges between $32 \%-89 \%$. In the same study, the incidence of aspiration pneumonia ranged between $4.3 \%-23 \%$. On the other hand, Pearson [5] and Leipzig [6] reported that the incidence of grade 1-2 aspiration ranges between $23.4 \%-80 \%$. In the present study, the rate of grade 1-2 aspiration in patients with a single/double arytenoid ranged between $25 \%-48 \%$, and the rate of grade $3-4$ aspiration ranged between $8 \%-58 \%$ (Table 1). These aspiration rates are consistent with literature. 
SCPL with persevering one arytenoid is oncologically safe, but different authors have debated its functional safety (aspiration-swallowing). A study has reported that the rate of aspiration and associated pneumonia is increased in patients who undergo SCPL preserving a single arytenoid [17]. Benito et al. [11] found higher rates of grade 2-3 aspiration in patients who underwent single arytenoid SCPL compared to grade $0-1$ aspiration. Yuce et al. [18] conducted a study of 32 patients, and found that the removal of the arytenoid is significant in terms of aspiration. Schwaab et al. [19] and Lewin et al. [16] stated that the aspiration rate is increased in patients with a single arytenoid, but this change is not significant [20]. Similarly, Lallemant et al. [20] also stated that leaving a single, intact arytenoid makes no functional difference. Bron et al. [21] reported that patients who undergo single arytenoidectomy have better swallowing-aspiration function. In the present study, group II patients had better aspiration rates in the first oral feeding period. Group I patients had better aspiration grades in the first month and the third month. However, we did not find significant differences in the three time points between group I and group II. A single arytenoid results from the presence of one-quarter of the posterior vocal cords in front of the intact arytenoid, and its compensation ability can cause this.

Enteral nutrition was continued until grade 4 aspiration. Parenteral antibiotic was administered to patients with aspiration pneumonia, their oral feeding was discontinued, and they were fed with a nasogastric tube. Patients with grade 2-3 aspiration were informed how they should perform the swallowing exercises, and were externed afterwards. These patients were contacted for regular follow-ups, and the aspiration rates of patients who were discharged for home rehabilitation improved rapidly. Gastrostomy was not performed on any patients with prolonged aspiration. Grade II aspiration was observed after the third month in 1 patient $(2 \%)$ who underwent SCPL with double arytenoid. The physical examination showed tongue base retraction, and arytenoids were unable to provide sufficient glottic closure without the help of the tongue base. One patient (2\%) underwent cricoid glossopexy reconstruction (including both arytenoids and hyoid), and the patient had grade 2 aspiration in the first month, and grade 1 aspiration in the third month. The removal of hyoid did not have a negative effect on aspiration. We were unable to analyze the statistical significance due to the presence of a single case. Oncological recurrence was not observed in any patients in group I and group II. None of the patients underwent total laryngectomy.

\section{CONFLICT OF INTEREST}

No potential conflict of interest relevant to this article was reported.

\section{REFERENCES}

1. Szyfter W, Leszczynska M, Wierzbicka M. Outcome after supracricoid laryngectomies in the material of ENT Department, Poznan University of Medical Sciences. Eur Arch Otorhinolaryngol. 2011 Jun;268(6):879-83.

2. Yuceturk AV, Gunhan K. Supracricoid laryngectomy: oncological and functional outcome. Kulak Burun Bogaz Ihtis Derg. 2004;13(34):57-61.

3. Aygenc E, Celikkanat S, Ozbek C, Dere H, Ozdem C. Functional outcomes after supracricoid partial laryngectomy. Kulak Burun Bogaz Ihtis Derg. 2002 Jan-Feb;9(1):54-8.

4. Laccourreye H, Laccourreye O, Weinstein G, Menard M, Brasnu D. Supracricoid laryngectomy with cricohyoidopexy: a partial laryngeal procedure for selected supraglottic and transglottic carcinomas. Laryngoscope. 1990 Jul;100(7):735-41.

5. Pearson BW. Subtotal laryngectomy. Laryngoscope. 1981 Nov;91 (11):1904-12.

6. Leipzig B. Neoglottic reconstruction following total laryngectomy: a reappraisal. Ann Otol Rhinol Laryngol. 1980 Nov-Dec;89(6 Pt 1): 534-7.

7. Cummings CW, Flint PW, Harker LA, Haughey BH, Richardson MA, Robbins KT, et al. Cummings otolaryngology head neck surgery. 4th ed.Ankara: Gunes Tip Kitapevi; 2007.

8. Marchese-Ragona R, De Grandis D, Restivo DA, Staffieri A, Marioni G, Pastore A. Recovery of swallowing disorders in patients undergoing supracricoid laryngectomy with botulinum toxin therapy. Ann Otol Rhinol Laryngol. 2003 Mar;112(3):258-63.

9. O’Neil KH, Purdy M, Falk J, Gallo L. The Dysphagia Outcome and Severity Scale. Dysphagia. 1999 Summer;14(3):139-45.

10. Rosenbek JC, Robbins JA, Roecker EB, Coyle JL, Wood JL. A penetration-aspiration scale. Dysphagia. 1996 Spring;11(2):93-8.

11. Benito J, Holsinger FC, Perez-Martin A, Garcia D, Weinstein GS, Laccourreye O. Aspiration after supracricoid partial laryngectomy: incidence, risk factors, management, and outcomes. Head Neck. 2011 May;33(5):679-85.

12. Naudo P, Laccourreye O, Weinstein G, Hans S, Laccourreye H, Brasnu D. Functional outcome and prognosis factors after supracricoid partial laryngectomy with cricohyoidopexy. Ann Otol Rhinol Laryngol. 1997 Apr;106(4):291-6.

13. Alajmo E, Fini-Storchi O, Agostini V, Polli G. Conservation surgery for cancer of the larynx in the elderly. Laryngoscope. 1985 Feb;95 (2):203-5.

14. Schindler A, Favero E, Capaccio P,Albera R, Cavalot AL, Ottaviani F. Supracricoid laryngectomy: age influence on long-term functional results. Laryngoscope. 2009 Jun;119(6):1218-25.

15. Pellini R, Manciocco V, Spriano G. Functional outcome of supracricoid partial laryngectomy with cricohyoidopexy: radiation failure vs previously untreated cases. Arch Otolaryngol Head Neck Surg. 2006 Nov;132(11):1221-5.

16. Lewin JS, Hutcheson KA, Barringer DA, May AH, Roberts DB, Holsinger FC, et al. Functional analysis of swallowing outcomes after supracricoid partial laryngectomy. Head Neck. 2008 May;30(5): 559-66.

17. Castro A, Sanchez-Cuadrado I, Bernaldez R, Del Palacio A, Gavilan J. Laryngeal function preservation following supracricoid partial laryngectomy. Head Neck. 2012 Feb;34(2):162-7.

18. Yuce I, Cagli S, Bayram A, Karasu F, Sati I, Guney E. The effect of arytenoid resection on functional results of cricohyoidopexy. Otolaryngol Head Neck Surg. 2009 Aug;141(2):272-5.

19. Schwaab G, Kolb F, Julieron M, Janot F, Le Ridant AM, Mamelle G, et al. Subtotal laryngectomy with cricohyoidopexy as first treatment procedure for supraglottic carcinoma: Institut Gustave-Roussy expe- 
rience (146 cases, 1974-1997). Eur Arch Otorhinolaryngol. 2001 Jul;258(5):246-9.

20. Lallemant JG, Bonnin P, el-Sioufi I, Bousquet J. Cricohyoepiglottopexy: long-term results in 55 patients. J Laryngol Otol. 1999 Jun; 113(6):532-7.
21. Bron L, Brossard E, Monnier P, Pasche P. Supracricoid partial laryngectomy with cricohyoidoepiglottopexy and cricohyoidopexy for glottic and supraglottic carcinomas. Laryngoscope. 2000 Apr;110 (4):627-34. 